\title{
Relevance of Toxicity Assessment in Wastewater Treatments: Case Study-Four Fenton Processes Applied to the Mineralization of C.I. Acid Red 14
}

\author{
Rajaa Idel-aouad, ${ }^{1}$ Manuel Valiente, ${ }^{1}$ Carmen Gutiérrez-Bouzán, ${ }^{2}$ Mercè Vilaseca, ${ }^{2}$ \\ Abdlrani Yaacoubi, ${ }^{3}$ Boumediene Tanouti, ${ }^{4}$ and Montserrat López-Mesas ${ }^{1}$ \\ ${ }^{1}$ Centre Grup de Tècniques de Separació en Química (GTS), Química Analítica, Departament de Química, \\ Universitat Autònoma de Barcelona, 08193 Bellaterra, Spain \\ ${ }^{2}$ Institut d'Investigació Tèxtil i Cooperació Industrial de Terrassa (INTEXTER), \\ Universitat Politècnica de Catalunya BarcelonaTech (UPC), Colom 15, 08222 Terrassa, Spain \\ ${ }^{3}$ Laboratory of Organic Applied Chemistry, Unit of Environmental and Experimental Methodology, \\ Faculty of Sciences Semlalia, University of Cadi Ayyad, 2390 Marrakech, Morocco \\ ${ }^{4}$ Laboratory of Condensed Matter and Environment, Faculty of Sciences Semlalia, University of Cadi Ayyad, 2390 Marrakech, Morocco \\ Correspondence should be addressed to Montserrat López-Mesas; montserrat.lopez.mesas@uab.cat
}

Received 17 November 2014; Accepted 21 May 2015

Academic Editor: Ricardo Jorgensen Cassella

Copyright (C) 2015 Rajaa Idel-aouad et al. This is an open access article distributed under the Creative Commons Attribution License, which permits unrestricted use, distribution, and reproduction in any medium, provided the original work is properly cited.

Fenton and Fenton-like processes, both in homogeneous and heterogeneous phases, have been applied to an aqueous solution containing the dye AR 14 in order to study the mineralization and toxicity of the solutions generated after color elimination. The mineralization of AR 14 occurred slower than the decolorization. The Microtox analysis of the treated solutions showed low toxicity intrinsic to the chemicals used in the process rather than the degradation products obtained after the treatment of the dye solution. The dye degradation for the Fenton oxidation process was initially faster than for the Fenton-like process but after a short time, the four processes showed similar degradation yields. All processes have shown good results being the heterogeneous process the most convenient since the $\mathrm{pH}$ adjustment is not necessary, the catalyst is recovered and reused and the generation of contaminated sludge is avoided.

\section{Introduction}

The growing industrialization has resulted in a dramatic increase of water pollution which has led to a greater environmental concern; that is, the textile industry can release about $15 \%$ of the dye into the effluents during the textile dyeing. The discharge of these effluents into natural stream and rivers poses severe problems, because the presence of small amounts of dyes (below 1 ppm) is clearly visible and influences the water environment considerably [1]. Thousands of scientific studies have been focused on wastewater remediation and a wide variety of treatments have been proposed such as biological and traditional physical techniques [2], advanced oxidation processes (AOPs), and electrochemical methods [3-5]. One of the most important AOPs is the oxidizing process based on the homogeneous Fenton reagent $\left(\mathrm{Fe}^{2+} / \mathrm{H}_{2} \mathrm{O}_{2}\right)[6,7]$. The mixture of ferrous ion and hydrogen peroxide in the Fenton's reagent generates hydroxyl radical $\left(\mathrm{OH}^{*}\right)$ in situ [8], according to

$$
\mathrm{Fe}^{2+}+\mathrm{H}_{2} \mathrm{O}_{2} \longrightarrow \mathrm{Fe}^{3+}+\mathrm{OH}^{-}+\mathrm{OH}^{*}
$$

The $\mathrm{Fe}^{3+}$ produced in this reaction reacts with $\mathrm{H}_{2} \mathrm{O}_{2}$ to regenerate $\mathrm{Fe}^{2+}$ as shown in (2) and (3). On the other hand, instead of generating $\mathrm{Fe}^{3+}$, the ion can be directly added to the solution, replacing the $\mathrm{Fe}^{2+}$, in a process called Fentonlike $\left(\mathrm{Fe}^{3+} / \mathrm{H}_{2} \mathrm{O}_{2}\right)$ :

$$
\begin{aligned}
& \mathrm{Fe}^{3+}+\mathrm{H}_{2} \mathrm{O}_{2} \longrightarrow \mathrm{Fe}(\mathrm{OOH})^{2+}+\mathrm{H}^{+} \\
& \mathrm{Fe}(\mathrm{OOH})^{2+} \longrightarrow \mathrm{Fe}^{2+}+\mathrm{HO}_{2}{ }^{\cdot}
\end{aligned}
$$


The impossible recuperation of the catalyst, a narrow active range of $\mathrm{pH}(3-5)$, and the need of removing the iron compounds from the purified effluent are disadvantages that strongly restrict the possible application of this process [9]. A solution to the problem could be the use of heterogeneous solid Fenton catalysts, such as clays, silicas, and zeolites whose recovery from water and regeneration are easy to perform [10-12]. These materials have demonstrated being effective catalysts for the oxidative breakdown of phenol [13] and some textile dyes in water [14] among others.

Usually these studies include a conscientious analytical study on pollutants determination or even on degradation mechanisms, but the evaluation of effluent toxicity is generally not carried out. However, the evaluation of wastewaters should include toxicity tests to complement the chemical characterization. Toxicity tests have gained importance since many substances are toxic to living beings at levels below chemical detection limits. Then, a combined approach using instrumental methods for chemical analysis and bioassays for ecotoxicological testing would be extremely important to hazard/risk assessment of wastewater treatment plant discharges [15]. These tests can be performed with simple equipment based on the use of a bacterium, alga, or crustacean. Despite their simplicity, speed, and low cost, they provide very useful information [16]. Several toxicity methods can be used, with Microtox being one of the most popular ones.

Microtox assay is a biosensor-based measurement system for toxicity evaluation, mainly used for water and wastewater assessment $[17,18]$. It is widely accepted as a standard bioassay for rapid and accurate toxicity monitoring $[19,20]$ because it provides a rapid and effective way to detect toxicity caused by a wide range of organic and inorganic contaminants.

In this work, the Microtox toxicity test is applied to evaluate the toxic effect of different treatments on the mineralization of the acid dye C.I. Acid Red 14 (AR 14) in aqueous medium (Fenton and Fenton-like processes in homogeneous and heterogeneous phases). This dye has been the one chosen as a model pollutant because acid dyes are the most widely used in many industrial sectors, such as alimentary, pharmaceutical, chemical, and textile ones.

AR 14 is classified as nontoxic, even food grade, but at the concentrations required to give intense color, it can cause some unpleasant reactions, such as lung, skin, and eye irritation and brain fog. In fact, safety sheets provide a long list of safety precautions [21]. Also, a possible link between the consumption of this artificial dye and an increased hyperactivity in children has been stablished [22]. In this concern as for precautionary principle, the European regulatory community reduced the acceptable daily intake for food colorings.

\section{Experimental}

2.1. Dye and Chemicals. Basovit Red 440 E $\left(\mathrm{C}_{20} \mathrm{H}_{14} \mathrm{O}_{7} \mathrm{~N}_{2} \mathrm{~S}_{2} \mathrm{Na}_{2}\right.$, Figure 1), which is the commercial name of C.I. Acid Red 14 [20], was purchased from Sigma Aldrich (Spain) and used without further purification. It is chemically classified as monoazo, with bluish red color, molecular weight of $502.44 \mathrm{~g} / \mathrm{mol}$, and $\lambda_{\max }$ of $516 \mathrm{~nm}$. The salts $\left(\mathrm{NH}_{4}\right)_{2} \mathrm{Fe}\left(\mathrm{SO}_{4}\right)_{2} \cdot 6 \mathrm{H}_{2} \mathrm{O}$ and $\mathrm{Fe}\left(\mathrm{NO}_{3}\right)_{3} \cdot 9 \mathrm{H}_{2} \mathrm{O}$ were

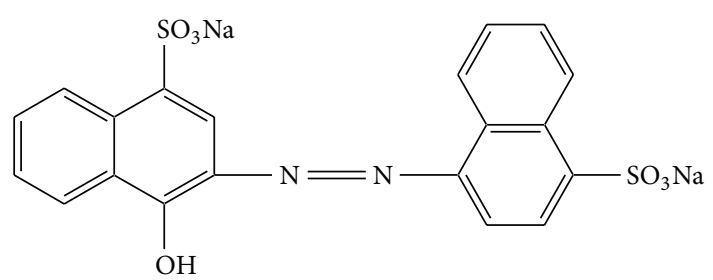

FIGURE 1: Chemical structure of AR 14.

purchased from Panreac (Spain) and used for the Fenton and Fenton-like processes, respectively, as well as for the catalysts preparation. $\mathrm{H}_{2} \mathrm{O}_{2}(35 \% \mathrm{w} / \mathrm{w})$ was from FLUKA (Spain). $\mathrm{H}_{2} \mathrm{SO}_{4}$ and $\mathrm{NaOH}(0.1 \mathrm{M})$ were from Scharlau (Spain) and used to adjust the $\mathrm{pH}$. All the solutions were prepared with MilliQ or double deionized water. The catalysts were prepared from commercially available ZeolystTM (zeolite Y), produced by Zeolyst International, USA. The zeolite Y-type CBV 712, in its ammonium cation form, has a surface area of $730 \mathrm{~m}^{2} / \mathrm{g}$, a $\mathrm{SiO}_{2} / \mathrm{Al}_{2} \mathrm{O}_{3}$ molar ratio of 12 , and $\mathrm{Na}_{2} \mathrm{O}$ weight $\%$ of 0.05 . It is well known that the unit cell size of $\mathrm{Y}$ zeolite is about $24.33-24.35 \AA$ (not provided by the manufacturer) $[23,24]$.

\subsection{Catalysts Preparation and Characterization. Heteroge-} neous Fenton catalyst Fe(III)-zeolite Y and Fe(II)-zeolite Y were prepared from zeolite $\mathrm{Y}$ through a cation exchange process [6]. For preparing the Fe(III)-zeolite Y, the zeolite was ion exchanged with an excess of $0.05 \mathrm{M} \mathrm{Fe}\left(\mathrm{NO}_{3}\right)_{3} \cdot 9 \mathrm{H}_{2} \mathrm{O}$ for $1 \mathrm{~h}$ at room temperature. For the preparation of $\mathrm{Fe}$ (II)-zeolite $\mathrm{Y}$, zeolite $\mathrm{Y}$ was ion exchanged with an excess of $0.05 \mathrm{M}$ of $\left(\mathrm{NH}_{4}\right)_{2} \mathrm{Fe}\left(\mathrm{SO}_{4}\right)_{2} \cdot 6 \mathrm{H}_{2} \mathrm{O}$ for $1 \mathrm{~h}$ under $\mathrm{N}_{2}$ atmosphere at ambient temperature to avoid the oxidation of the iron. The catalyst already prepared was then filtered, thoroughly washed three times with distilled water, and dried in an oven under air at $60^{\circ} \mathrm{C}$ overnight. Characterization of the heterogeneous catalysts was carried out by X-ray diffraction (XRD) measured with a Philips XPert MPD using $\mathrm{Cu} K \alpha$ radiation at $40 \mathrm{kV}$ and $30 \mathrm{~mA}$ with a scanning speed of $2 \theta=2 \mathrm{~S}^{-1}$. The total amount of iron loaded onto the Fe(III)-zeolite Y and Fe(II)-zeolite $\mathrm{Y}$ was determined by using Portable X-Ray Fluorescence equipment (FP-XRF, Alpha-6500R, Innov-X Systems, Inc., Woburn, MA, USA), which consists in a tube-type energy dispersive instrument with a tungsten cathode and a silver anode that can generate $\mathrm{X}$-rays in the energy range 10 to $40 \mathrm{keV}$ and $10-50 \mu \mathrm{A}$.

2.3. Fenton-Like and Fenton Experiments. The homogeneous Fenton-like and Fenton processes were carried out by adding, respectively, the needed amount of $\mathrm{Fe}\left(\mathrm{NO}_{3}\right)_{3} \cdot 9 \mathrm{H}_{2} \mathrm{O}$ or $\left(\mathrm{NH}_{4}\right)_{2} \mathrm{Fe}\left(\mathrm{SO}_{4}\right)_{2} \cdot 6 \mathrm{H}_{2} \mathrm{O}$ to $100 \mathrm{~mL}$ of solution of the dye to obtain $2.17 \mathrm{mM}$ of iron ions. Five minutes later, $750 \mu \mathrm{L}$ of $\mathrm{H}_{2} \mathrm{O}_{2}$ (35\%) was added and the time for the kinetic studies started to count.

For the heterogeneous process, Fe-zeolite Y prepared as previously described was used at the optimized conditions set 
in our previous study [25] and as follows: initial dye concentration of $50 \mathrm{ppm}$, concentration of $\mathrm{H}_{2} \mathrm{O}_{2} 8.7 \mathrm{mM}$, temperature $80^{\circ} \mathrm{C}$, and initial $\mathrm{pH}$ value close to 5.96 (natural $\mathrm{pH}$ of the solution). These values were adopted for comparing the different homogeneous and heterogeneous Fenton and Fentonlike processes. Because the amount of iron loaded to each of the different catalysts prepared was different, the amount of the catalysts added to the dye solution was always calculated in order to ensure the same amount of iron ions added to the solution (approximately 2.5 and $15 \mathrm{~g} / \mathrm{L}$ for Fe(III)-zeolite Y and $\mathrm{Fe}(\mathrm{II})$-zeolite Y, resp.).

Dye oxidation experiments were carried out in $250 \mathrm{~mL}$ thermostatic glass reactor equipped with a magnetic stirrer, thermometer, and $\mathrm{pH}$ electrode.

2.4. Kinetics of Decolorization. At preselected time intervals, $1 \mathrm{~mL}$ of sample was taken from the glass reactor, filtrated through a $0.45 \mu \mathrm{m}$ Millipore filters, and analyzed or frozen until being analyzed (procedure that was corroborated to stop the reaction). Filters were tested in order to check if the dye was absorbed on them and no concentration change was observed. The degree of decolorization of the dye was spectrophotometrically followed measuring the absorbance using a UNICAM UV-Visible spectrophotometer selected at the wavelength with highest absorbance, $\lambda_{\max }=516 \mathrm{~nm}$. The dye concentration was quantified through a calibration curve according to the Lambert-Beer law. The degree of decolorization was calculated using

$$
\text { Decolourization efficiency }(\%)=\frac{C_{0}-C_{t}}{C_{0}} \times 100 \text {, }
$$

where $C_{0}$ and $C_{t}$ are the concentrations $(\mathrm{mg} / \mathrm{L})$ of the dye at time 0 and $t$, respectively.

In order to model the kinetics of the decolorization, the pseudo-first-order rate equation was used:

$$
-\operatorname{Ln} \frac{C_{t}}{C_{o}}=K t
$$

where $C_{t}$ is the dye concentration at time $t(\mathrm{~mol} / \mathrm{L}), C_{o}$ the dye concentration at initial time $(t=0), k$ the pseudo-firstorder rate constant of consumption $\left(\mathrm{min}^{-1}\right)$, and $t$ the time of reaction in minutes.

An ICP-OES, Iris Intrepid II (Thermo Electron, USA), was used for the quantitative determination of iron ions in solution. Sample introduction was performed by a peristaltic pump $(1.5 \mathrm{~mL} / \mathrm{min})$ connected to a Meinhard nebulizer and then to a cyclone spray chamber. The nebulizer gas was $21 \mathrm{~mL}$ Ar/min. These parameters were optimal conditions for this instrument. For every ten samples measured, a QC standard of iron was performed.

2.5. Mineralization and Toxicity Tests. Total organic carbon (TOC) concentration was carried out in a TOC analyzer (Shimadzu TOC-5050A) to evaluate the mineralization of the dye after the four processes. The mineralization efficiency of the dye was calculated using

$$
\begin{gathered}
\text { Mineralization efficiency (\%) } \\
=\frac{\mathrm{TOC}_{0}-\mathrm{TOC}_{t}}{\mathrm{TOC}_{0}} \times 100,
\end{gathered}
$$

where $\mathrm{TOC}_{t}$ is the value of TOC obtained at time $t$ and $\mathrm{TOC}_{0}$ corresponds to the initial value of TOC.

The aqueous dye solutions of Acid Red 14 after the four oxidation processes were analyzed by bioluminescence assay in a Microtox 500 apparatus from MICROBICS. Tests were performed using the luminescence bacterium Vibrio fischeri, method of lyophilized bacteria [26], according to the international standard ISO 11348-3:2007. The Microtox organism Vibrio fischeri (Photobacterium phosphoreum) is a bioluminescent organism that produces light as a by-product of its normal metabolism and has demonstrated the highest sensitivity across a broad range of toxicants. The Microtox Acute Toxicity Test measures the relative toxicity of the water sample by recording the light output of the luminescent bacteria before and after exposure to the sample and statistically processes raw data to produce reports on the toxicity of the sample. The level of toxicity is proportional to the inhibition of light production [27]. Luminescent bacteria and all reagents required for the assay were obtained from MICROBICS. The commercially lyophilized bacteria were reconstituted just prior to analysis and incubated with the corresponding sample at $15^{\circ} \mathrm{C}$ following the mentioned protocol. Effects were calculated as percent of inhibition and based on the decrease of bioluminescence in the samples related to the control solution. Toxicity is expressed as the concentration of compound that produces $50 \%$ of bioluminescence inhibition $\left(\mathrm{EC}_{50}\right)$. When the sample is constituted by a mixture of compounds or contains unknown compounds the result is expressed as percentage of sample that produces $\mathrm{EC}_{50}$. In order to make a better interpretation of the result, the toxicity impact index $\left(\mathrm{TII}_{50}\right)$, also called Equitox $/ \mathrm{m}^{3}$, is used and defined as in (7) where $\mathrm{TII}_{50}$ is directly proportional to the toxicity of the sample:

$$
\mathrm{TII}_{50}=\frac{100}{\mathrm{EC}_{50}}
$$

All the analyses were carried out in duplicate and results are expressed as the average \pm RSD (95\% of confidence level).

\section{Results and Discussion}

3.1. Catalysts Characterization. Fe(III)-zeolite Y and Fe(II)zeolite $\mathrm{Y}$ were checked by powder X-ray diffraction. This analysis showed that the catalyst had a typical USY zeolite structure and no amorphous material was present (Figure 2). Introduction of iron cations into USY zeolite via ion exchange had virtually no effect on its crystalline structure. The total amount of iron loaded onto Fe(III)-zeolite Y and Fe(II)zeolite $\mathrm{Y}$ was determined by $\mathrm{X}$-ray fluorescence, found to be, respectively, $12.12 \times 10^{-2}$ and $2.02 \times 10^{-2} \mathrm{~g}$ of Fe/g zeolite $\mathrm{Y}$. 


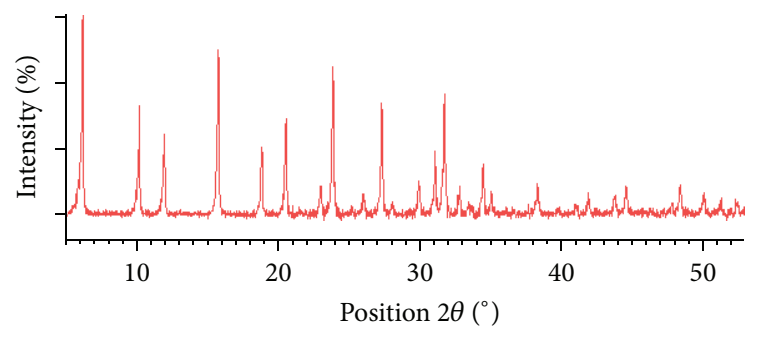

(a)

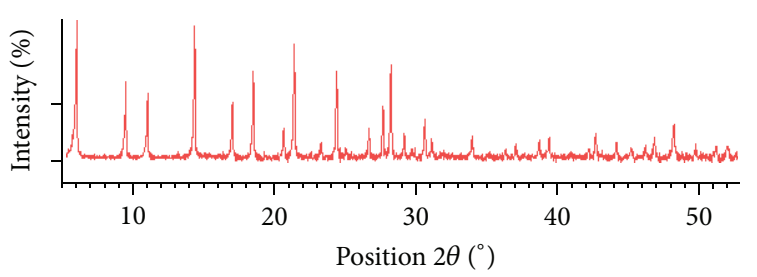

(b)

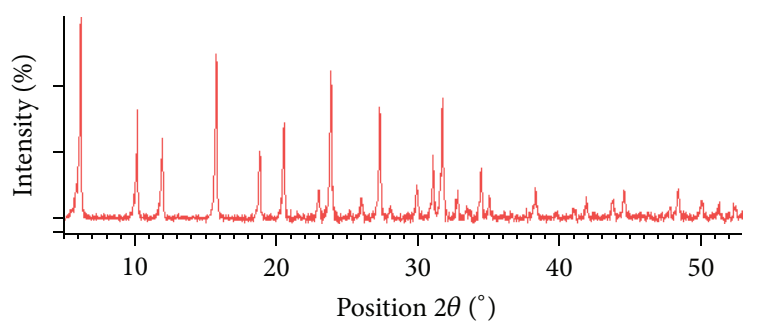

(c)

FIGURE 2: XRD patterns of (a) Fe(II)-Y zeolite, (b) Fe(III)-Y zeolite, and (c) zeolite.

3.2. Acid Red 14 Decolorization by Heterogeneous and Homogeneous Fenton Processes. It was verified that for both homogeneous processes, Fenton and Fenton-like, the simple addition of the salts used for the solution of the dye in the absence of $\mathrm{H}_{2} \mathrm{O}_{2}$ had no effect on the AR 14 spectra. Then, when the hydrogen peroxide was added, the color of the solution changed from clear red to turbid brown within $30 \mathrm{~s}$. As the reaction progressed, the dark color of the solution was changed to light yellow and after $30 \mathrm{~min}$ was clear and almost colorless indicating that the reaction was complete. Figures 3 and 4 show, respectively, a typical time-dependent UV-Vis spectrum of AR 14 under Fenton and Fenton-like processes. As it is seen, the absorption of the main band with a maximum at $516 \mathrm{~nm}$ decreased to finally disappear indicating that the AR 14 had been degraded. No new absorption bands appear in either the visible or ultraviolet regions.

AR 14 has negative sulfonate groups, which are repelled by the negatively charged zeolite surface which induces a relatively low adsorption capacity for natural zeolite. In fact, it has been found that the addition of $\mathrm{Fe}$ (III)-zeolite $\mathrm{Y}$ or $\mathrm{Fe}$ (II)zeolite $\mathrm{Y}$ without $\mathrm{H}_{2} \mathrm{O}_{2}$ does not evidence any change in the UV-Vis spectra of the dye solutions, even after $24 \mathrm{~h}$ of treatment. Figure 5 shows the UV-Vis spectra of the AR 14 solution for different contact time under heterogeneous Fenton-like process after the addition of $\mathrm{H}_{2} \mathrm{O}_{2}$ (see [25] for heterogeneous Fenton process). The absorption of the main peak

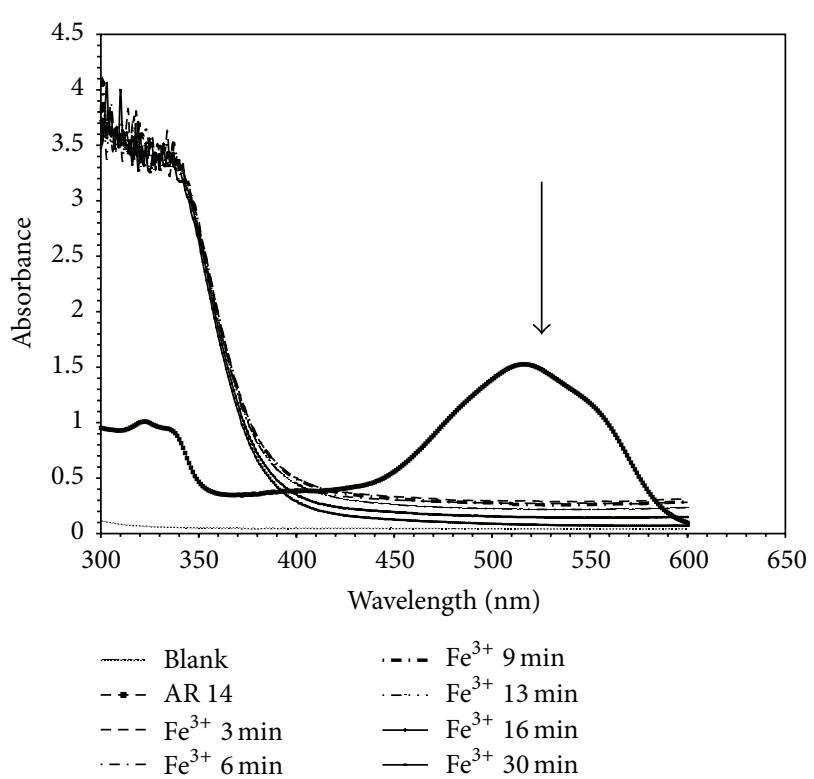

FIgURE 3: UV-Visible spectra changes of Acid Red 14 during Fentonlike process $\left(\mathrm{Fe}^{3+} / \mathrm{H}_{2} \mathrm{O}_{2}\right)$.

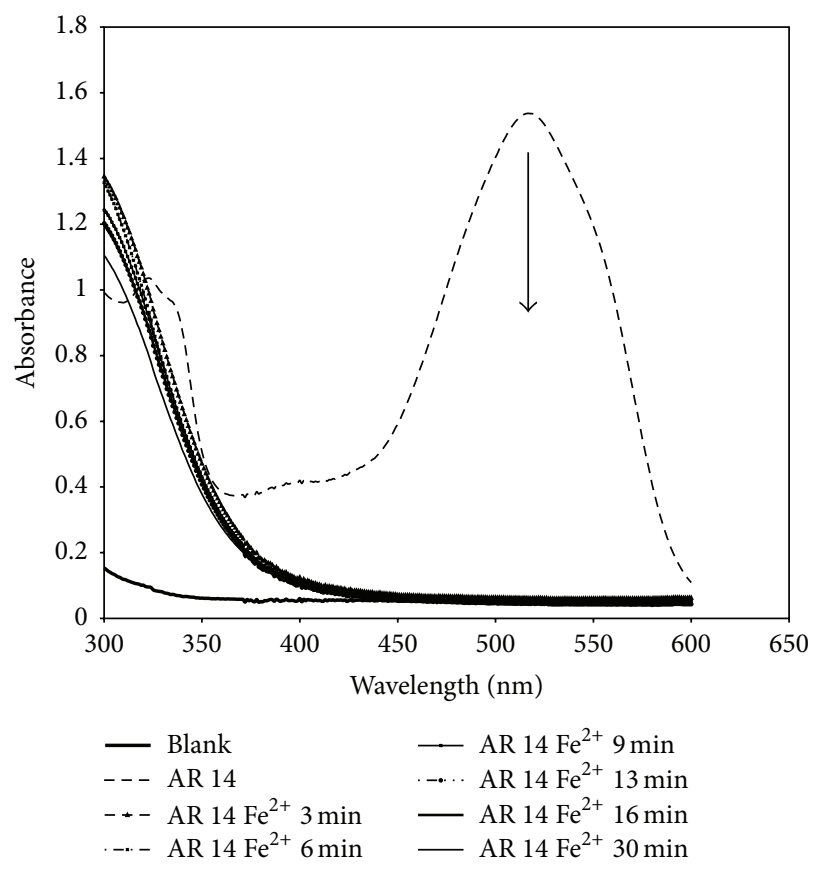

FIGURE 4: UV-Visible spectra changes of Acid Red 14 during Fenton process $\left(\mathrm{Fe}^{2+} / \mathrm{H}_{2} \mathrm{O}_{2}\right)$.

decreased as the reaction time increased to finally disappear indicating the degradation of the dye.

Figure 6 shows the variation of the dye decolorization for the four systems under study $\mathrm{Fe}^{2+} / \mathrm{H}_{2} \mathrm{O}_{2}, \mathrm{Fe}^{3+} / \mathrm{H}_{2} \mathrm{O}_{2}, \mathrm{Fe}(\mathrm{II})$ zeolite $\mathrm{Y} / \mathrm{H}_{2} \mathrm{O}_{2}$, and $\mathrm{Fe}(\mathrm{III})$-zeolite $\mathrm{Y} / \mathrm{H}_{2} \mathrm{O}_{2}$ at the optimized parameters. The yield of the dye decolorization was higher than $99 \%$ after $13 \mathrm{~min}$ for all the processes. At the beginning, the decolorization rate in homogeneous Fenton was much 


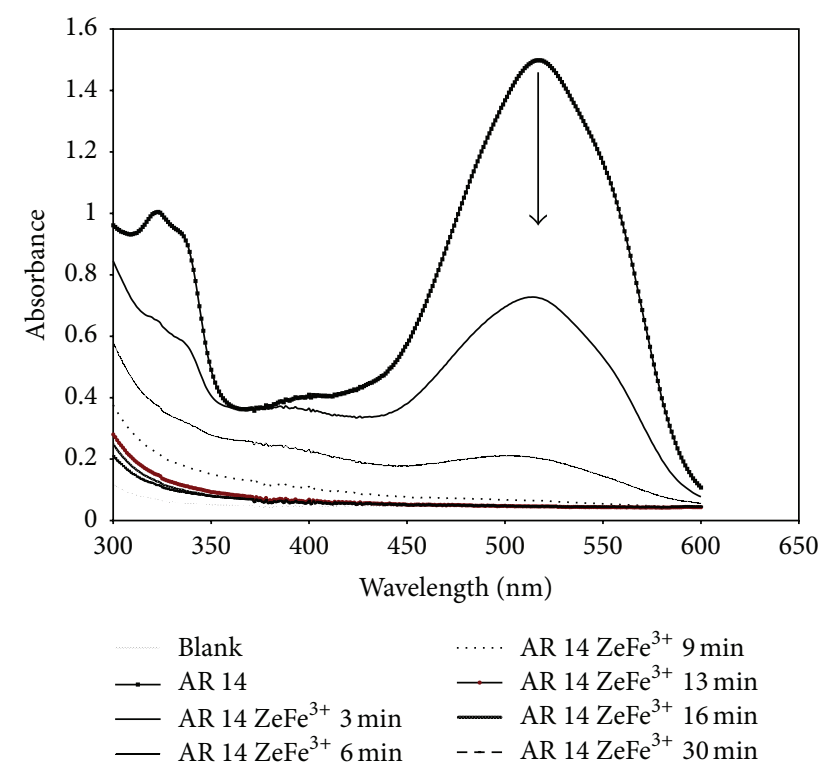

FIgURE 5: UV-Visible spectra changes of Acid Red 14 during Fe(III)$\mathrm{Y}$ zeolite $/ \mathrm{H}_{2} \mathrm{O}_{2}$ process.

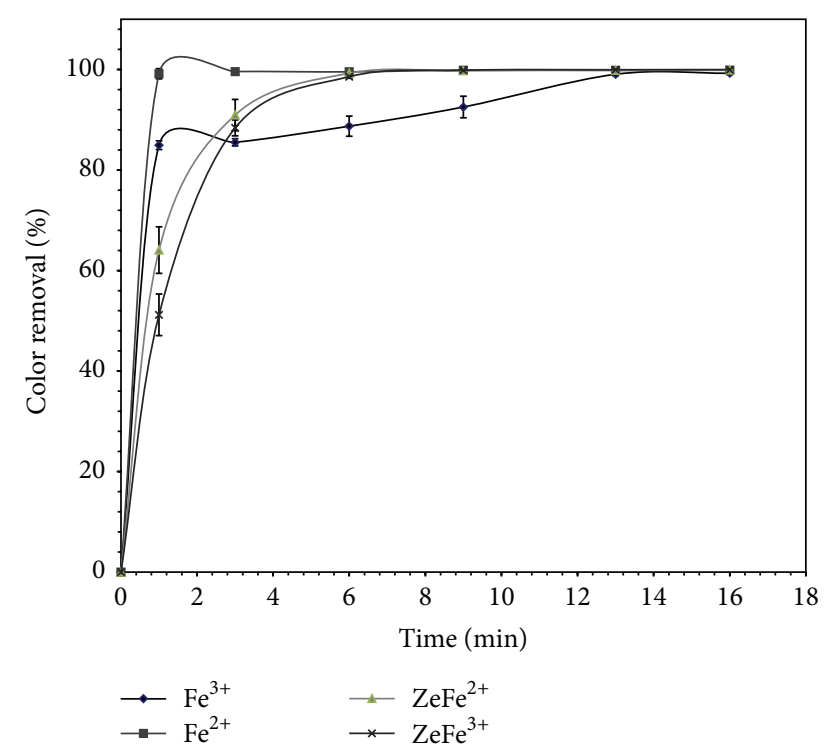

FIGURE 6: Color removal with time for the processes $\mathrm{Fe}^{2+} / \mathrm{H}_{2} \mathrm{O}_{2}$, $\mathrm{Fe}^{3+} / \mathrm{H}_{2} \mathrm{O}_{2}, \mathrm{Fe}(\mathrm{II})-\mathrm{Y}$ zeolite $/ \mathrm{H}_{2} \mathrm{O}_{2}$, and $\mathrm{Fe}(\mathrm{III})-\mathrm{Y}$ zeolite $/ \mathrm{H}_{2} \mathrm{O}_{2}$ at optimized parameters.

faster than in Fenton-like reaction (apparent rate constants $k=5.103$ and $1.9068 \mathrm{~min}^{-1}$, resp., calculated by (5)). This fact is probably due to the additional step involved in the Fentonlike system: the conversion of $\mathrm{Fe}^{3+}$ into $\mathrm{Fe}^{2+}$ to generate the free radicals. For the heterogeneous systems, slight difference was only observed at the beginning of the reaction $(k=0.9051$ for $\mathrm{Fe}(\mathrm{II})$-zeolite $\mathrm{Y} / \mathrm{H}_{2} \mathrm{O}_{2}$ and $0.6935 \mathrm{~min}^{-1}$ for $\mathrm{Fe}(\mathrm{III})$-zeolite $\mathrm{Y} / \mathrm{H}_{2} \mathrm{O}_{2}$ ). After a short period of three minutes, the degree of decolorization was similar for both processes (99\% after $9 \mathrm{~min})$.
TABLE 1: Results for the mineralization and toxicity tests.

\begin{tabular}{lcccc}
\hline Sample & TOC & $\mathrm{EC}_{50}$ & $\begin{array}{c}\mathrm{TII}_{50} \\
\left(\text { Equitox } / \mathrm{m}^{3}\right)\end{array}$ & $\begin{array}{c}\text { Blank } \\
\mathrm{TII}_{50}\end{array}$ \\
\hline $\mathrm{Fe}^{3+} / \mathrm{H}_{2} \mathrm{O}_{2}$ & $73 \pm 7 \%$ & & Nontoxic & \\
$\mathrm{Fe}^{2+} / \mathrm{H}_{2} \mathrm{O}_{2}$ & $91 \pm 4 \%$ & $6 \pm 3 \%$ & $20 \pm 11$ & 28 \\
$\mathrm{Fe}(\mathrm{III})$-zeolite & $86 \pm 1 \%$ & $2.3 \pm 0.3 \%$ & $45 \pm 6$ & 48 \\
$\mathrm{Y} / \mathrm{H}_{2} \mathrm{O}_{2}$ & & & & \\
$\mathrm{Fe}(\mathrm{II})-$ zeolite & $84 \pm 6 \%$ & $24 \pm 8 \%$ & $4 \pm 1$ & 7 \\
$\mathrm{Y} / \mathrm{H}_{2} \mathrm{O}_{2}$ & & & & \\
\hline
\end{tabular}

3.3. Mineralization and Microtox Analysis. TOC was measured for the initial dye solution and after $15 \mathrm{~min}$ of treatment for the homogenous and heterogeneous Fenton processes at the established conditions. The results of TOC removal of AR 14 are shown in Table 1. From these results, it is deduced that the mineralization of AR 14 proceeds slower than the decolorization, result that is in accordance with a dye bath degradation study by electrochemical treatment [4]. By this last technique, the color of a reactive dye solution $(1 \mathrm{~g} / \mathrm{L})$ was totally removed after $90 \mathrm{~min}$ of treatment but dye mineralization was much slower, with $10 \mathrm{~h}$ of electrochemical treatment being necessary to reach a TOC reduction of $81 \%$. This difference between decolorization and mineralization is attributed to the extent of the reactions. In the first case, the decolorization is simply achieved by breaking the azo linkages of the dye. However, the mineralization is reached when the organic matter has been fully destroyed to produce $\mathrm{CO}_{2}$ and $\mathrm{H}_{2} \mathrm{O}$. Because of this, the technique is proposed as a pretreatment to be carried out only on the colored wastewater, which must be segregated and decolorized previously to its incorporation to the biological treatment, combination that showed being very effective for the removal of color and organic matter [28].

The inhibitory effects produced by the different treatments on the bioluminescence of Vibrio fischeri were studied as previously described. For the different treatments, results of $\mathrm{EC}_{50}, \mathrm{TII}_{50}$, and blank expressed as $\mathrm{TII}_{50}$ demonstrated that the inhibitory effects due to the dye oxidation byproducts were very low. The only contribution to the contamination is the chemicals introduced by the process itself because the system under consideration showed in all cases nonsignificant differences with respect to the blanks (Table 1). The only exception found was for the Fenton-like system which did not show toxicity. To better understand the origin of the toxicity, new experiments with different amounts of zeolite $(2.5,15.0$, and $30.0 \mathrm{~g} / \mathrm{L})$ were carried out and results did not show any toxic effect. On the other hand, a solution containing $15.0 \mathrm{~g} / \mathrm{L}$ of zeolite with $8.7 \mathrm{mM}$ of $\mathrm{H}_{2} \mathrm{O}_{2}$ was also analyzed. The $\mathrm{TII}_{50}$ showed a value of 43.5 which increased to 125 when the same amount of $\mathrm{H}_{2} \mathrm{O}_{2}$ without zeolite was analyzed, meaning that the toxicity was coming exclusively by the remaining hydrogen peroxide and that the heating was not sufficient to completely eliminate it after the treatment. All the experiments were always performed in the same way as the heterogeneous experiment previously described. 
3.4. Leaching and Stability Tests for the Heterogeneous Processes. During the process, iron ions can be released from the zeolite to the solution generating a secondary pollution and degrading the catalyst performance. In order to measure the amount of iron released, after each experiment the solution was filtered and analyzed by ICP-OES. The concentration of the iron ions released to the solution was found to be $0.2 \pm 0.1 \mathrm{ppm}$ and $0.6 \pm 0.2 \mathrm{ppm}$. These results show that the decolorization and mineralization are mainly due to the heterogeneous catalyst activity ( $\mathrm{Fe}(\mathrm{II})$-zeolite $\mathrm{Y} / \mathrm{H}_{2} \mathrm{O}_{2}$ and $\mathrm{Fe}(\mathrm{III})$-zeolite $\mathrm{Y} / \mathrm{H}_{2} \mathrm{O}_{2}$ ) and not to the leached iron ions.

Another important property of a catalyst is its long-term stability. In order to assess the catalytic activity of the zeolite during successive experiments, zeolite recovered by filtration from the solution after the treatment was washed with MilliQ water, dried at $60^{\circ} \mathrm{C}$ (overnight), and then tested again under the same reaction conditions. The color removal percentage for the three consecutive cycles was $99.96 \pm 0.01,99.8 \pm 0.1$, and $93 \pm 1$ for $\mathrm{Fe}$ (II)-zeolite $\mathrm{Y} / \mathrm{H}_{2} \mathrm{O}_{2}$ and $99.77 \pm 0.04,98.5 \pm$ 0.5 , and $94 \pm 1$ for $\mathrm{Fe}(\mathrm{III})$-zeolite $\mathrm{Y} / \mathrm{H}_{2} \mathrm{O}_{2}$ catalytic studies. As it is seen, when the zeolite was reused three consecutive times, its catalytic activity was still higher than $90 \%$, indicating a very low deactivation, which could be produced by the release of iron to the media or by deactivation of the catalyst.

\section{Conclusions}

In the present work, TOC and Microtox have been used to complement the information obtained after Fenton and Fenton-like processes for mineralization and toxicity, respectively. The homogeneous treatment with $\mathrm{Fe}^{2+} / \mathrm{H}_{2} \mathrm{O}_{2}$ is very effective for the complete removal of color after $3 \mathrm{~min}$ and only 15 minutes is needed to get a mineralization higher than $90 \%$. On the other hand, the heterogeneous process achieves total decolorization in 6 minutes with a mineralization higher than $84 \%$, with the mineralization of the dye, in all cases, being slower than the decolorization. The catalyst can be recovered and reused at least three times as the iron is not released to the solution avoiding the generation of the nondesired sludge, from an economical and environmental point of view, which increases the overall costs of the Fenton process. Another great advantage of zeolite $\mathrm{Y}$ process versus homogeneous Fenton process is the operation $\mathrm{pH}$ range. Whereas in the homogeneous process a strong acid $\mathrm{pH}$ value is required, in the heterogeneous one it is possible to work at a wider $\mathrm{pH}$ range which is very convenient because effluents may present a wide range of $\mathrm{pH}$ depending on the type of dyes used, thus reducing the costs of $\mathrm{pH}$ adjusting before discharge and associated problems. Microtox analysis showed that for all the processes the low toxicity generated was produced only by the residual $\mathrm{H}_{2} \mathrm{O}_{2}$.

\section{Conflict of Interests}

The authors declare that there is no conflict of interests regarding the publication of this paper.

\section{Acknowledgments}

Rajaa Idel-aouad acknowledges the financial support from the European Union (IMAGEEN, Erasmus Mundus Program) that enabled her to move from the University of Cadi Ayyad to Universitat Autònoma de Barcelona to carry out the study. The Spanish Ministry for Economy and Competitiveness (Projects CTM2012-30970 and CTM2012-31461) is acknowledged for the financial support to the experimental work carried out in the present study. M. Raspall from INTEXTER is kindly acknowledged for her technical support in the TOC analysis.

\section{References}

[1] N. Daneshvar, D. Salari, and A. R. Khataee, "Photocatalytic degradation of azo dye acid red 14 in water: investigation of the effect of operational parameters," Journal of Photochemistry and Photobiology A: Chemistry, vol. 157, no. 1, pp. 111-116, 2003.

[2] K. Pirkanniemi and M. Sillanpaa, "Heterogeneous water phase catalysis as an environmental application: a review," Chemosphere, vol. 48, no. 10, pp. 1047-1060, 2002.

[3] Z. Eren, F. N. Acar, and N. H. Ince, "Fenton and fenton-like oxidation of CI basic yellow 51: a comparative study," Coloration Technology, vol. 126, no. 6, pp. 337-341, 2010.

[4] V. López-Grimau and M. C. Gutiérrez, "Decolourisation of simulated reactive dyebath effluents by electrochemical oxidation assisted by UV light," Chemosphere, vol. 62, no. 1, pp. 106-112, 2006.

[5] M. Riera-Torres and M.-C. Gutiérrez, "Colour removal of three reactive dyes by UV light exposure after electrochemical treatment," Chemical Engineering Journal, vol. 156, no. 1, pp. 114$120,2010$.

[6] M. Neamţu, C. Zaharia, C. Catrinescu, A. Yediler, M. Macoveanu, and A. Kettrup, "Fe-exchanged Y zeolite as catalyst for wet peroxide oxidation of reactive azo dye Procion Marine H-EXL," Applied Catalysis B: Environmental, vol. 48, no. 4, pp. 287-294, 2004.

[7] E. Guélou, J. Barrault, J. Fournier, and J.-M. Tatibouët, "Active iron species in the catalytic wet peroxide oxidation of phenol over pillared clays containing iron," Applied Catalysis B: Environmental, vol. 44, no. 1, pp. 1-8, 2003.

[8] S. S. Ashraf, M. A. Rauf, and S. Alhadrami, "Degradation of methyl red using Fenton's reagent and the effect of various salts," Dyes and Pigments, vol. 69, no. 1-2, pp. 74-78, 2006.

[9] F. Martínez, G. Calleja, J. A. Melero, and R. Molina, "Heterogeneous photo-Fenton degradation of phenolic aqueous solutions over iron-containing SBA-15 catalyst," Applied Catalysis B: Environmental, vol. 60, no. 3-4, pp. 181-190, 2005.

[10] S. Navalon, M. Alvaro, and H. Garcia, "Heterogeneous Fenton catalysts based on clays, silicas and zeolites," Applied Catalysis B: Environmental, vol. 99, no. 1-2, pp. 1-26, 2010.

[11] E. G. Garrido-Ramírez, B. K. G. Theng, and M. L. Mora, “Clays and oxide minerals as catalysts and nanocatalysts in Fenton-like reactions-a review," Applied Clay Science, vol. 47, no. 3-4, pp. 182-192, 2010.

[12] J. Chen, "Immobilisation of Iron-containing materials onto supporting materials in heterogeneous Fenton system: a review," Advanced Materials Research, vol. 955-959, pp. 569-580, 2014. 
[13] J. O. Méndez, J. H. Melián, J. Araña, J. D. Rodríguez, O. G. Díaz, and J. P. Peña, "Detoxification of waters contaminated with phenol, formaldehyde and phenol-formaldehyde mixtures using a combination of biological treatments and advanced oxidation techniques," Applied Catalysis B: Environmental, vol. 163, pp. 6373, 2015.

[14] N. H. M. Azmi, V. M. Vadivelu, and B. H. Hameed, "Iron-clay as a reusable heterogeneous Fenton-like catalyst for decolorization of Acid Green 25," Desalination and Water Treatment, vol. 52, no. 28-30, pp. 5583-5593, 2014.

[15] E. P. C. Lai, "Bioassay kits for ecotoxicological testing of wastewaters with nanoparticles," Biochemistry \& Analytical Biochemistry, vol. 2, article el39, 2013.

[16] E. Mendonça, A. Picado, S. M. Paixão et al., "Ecotoxicity tests in the environmental analysis of wastewater treatment plants: case study in Portugal," Journal of Hazardous Materials, vol. 163, no. 2-3, pp. 665-670, 2009.

[17] F. D. L. Leusch, S. J. Khan, M. M. Gagnon et al., "Assessment of wastewater and recycled water quality: a comparison of lines of evidence from in vitro, in vivo and chemical analyses," Water Research, vol. 50, pp. 420-431, 2014.

[18] O. J. Hao, C.-J. Shin, C.-F. Lin, F.-T. Jeng, and Z.-C. Chen, "Use of Microtox tests for screening industrial wastewater toxicity," Water Science and Technology, vol. 34, no. 10, pp. 43-50, 1996.

[19] S. Parvez, C. Venkataraman, and S. Mukherji, "A review on advantages of implementing luminescence inhibition test (Vibrio fischeri) for acute toxicity prediction of chemicals," Environment International, vol. 32, no. 2, pp. 265-268, 2006.

[20] Society of Dyers and Colourists, "Colour index international," Tech. Rep. SDC/AATCC 1-9, Bradford, UK, 1992.

[21] Acid Red 14, Safety Data Sheet, https://www.spectrumchemical .com/MSDS/A0591.pdf.

[22] FDA, Background Document for the Food Advisory Committee: Certified Color Additives in Food and Possible Association with Attention Deficit Hyperactivity Disorder in Children, 2011.

[23] A. Corma, A. Martinez, S. Pergher, S. Peratello, C. Perego, and G. Bellusi, "Hydrocraking-hydroisomerization of n-decane on amorphous silica-alumina with uniform pore diameter," Applied Catalysis A: General, vol. 152, no. 1, pp. 107-125, 1997.

[24] J. Zheng, M. Guo, and C. Song, "Characterization of Pd catalysts supported on USY zeolites with different $\mathrm{SiO}_{2} / \mathrm{Al}_{2} \mathrm{O}_{3}$ ratios for the hydrogenation of naphthalene in the presence of benzothiophene," Fuel Processing Technology, vol. 89, no. 4, pp. 467474, 2008.

[25] R. Idel-aouad, M. Valiente, A. Yaacoubi, B. Tanouti, and M. López-Mesas, "Rapid decolourization and mineralization of the azo dye C.I. Acid Red 14 by heterogeneous Fenton reaction," Journal of Hazardous Materials, vol. 186, no. 1, pp. 745-750, 2011.

[26] ISO, ISO 11348-3: Water Quality: Determination of the Inhibitory Effect of Water Samples on the Light Emission of Vibrio fischeri (luminiscent Bacteria Test), International Organization for Standardization, London, UK, 2007.

[27] E. J. Martin, "Toxicity testing system: does it belong in the environmental industry?" in Proceedings of the Remediation Technologies Symposium, 2009.

[28] M. Vilaseca, M.-C. Gutiérrez, V. López-Grimau, M. LópezMesas, and M. Crespi, "Biological treatment of a textile effluent after electrochemical oxidation of reactive dyes," Water Environment Research, vol. 82, no. 2, pp. 176-182, 2010. 

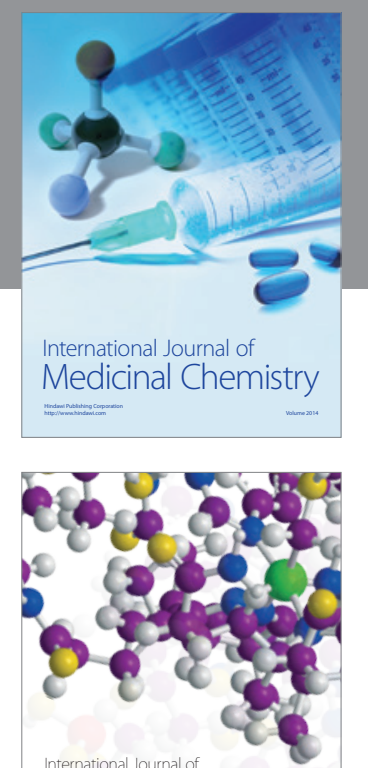

\section{Carbohydrate} Chemistry

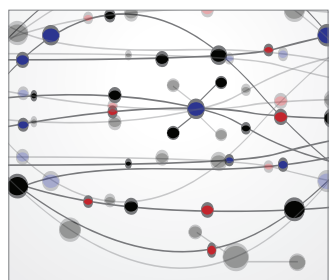

The Scientific World Journal
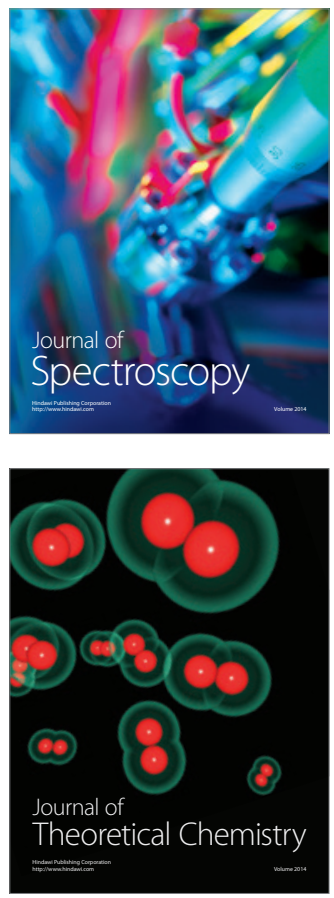
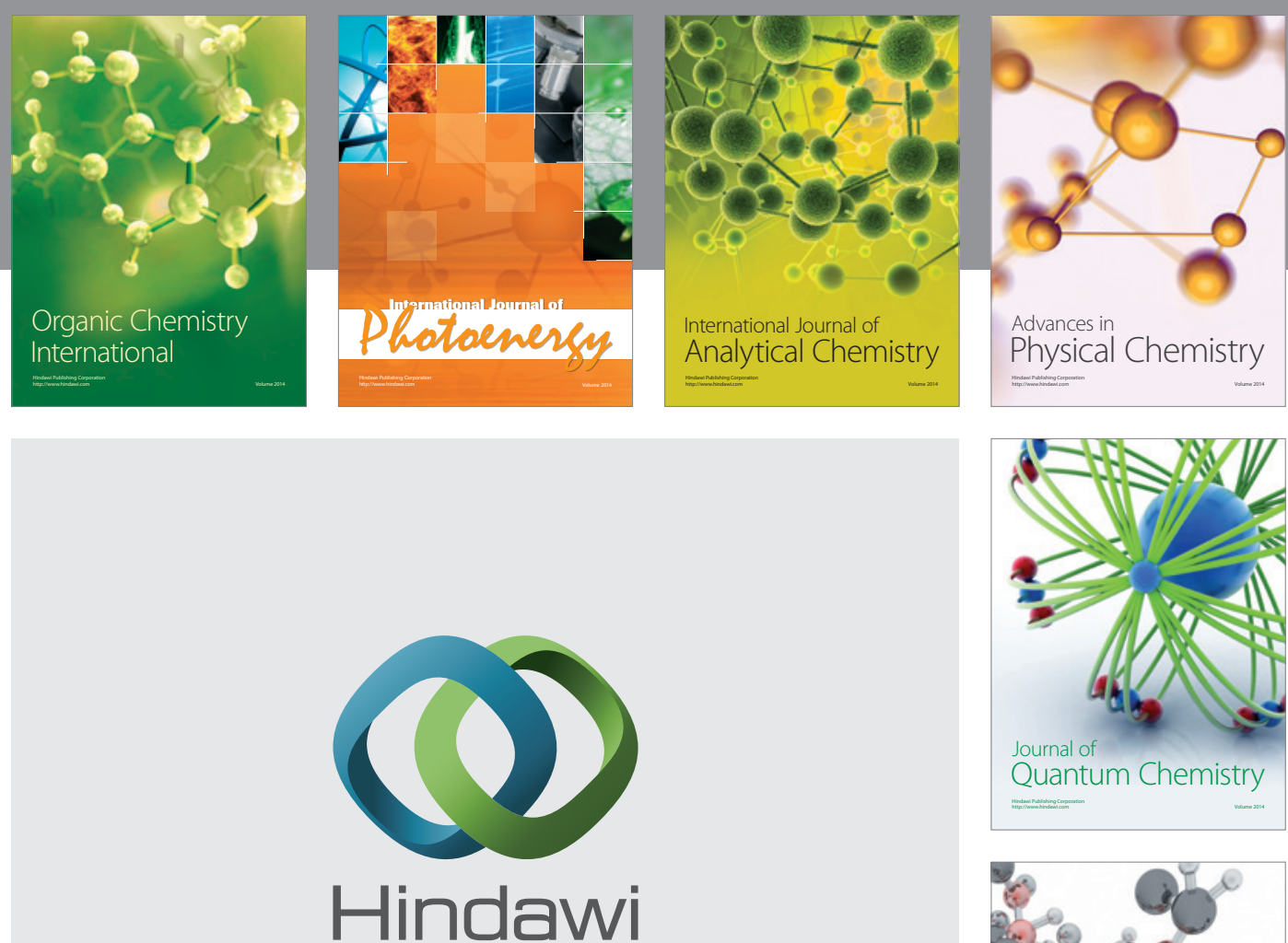

Submit your manuscripts at

http://www.hindawi.com

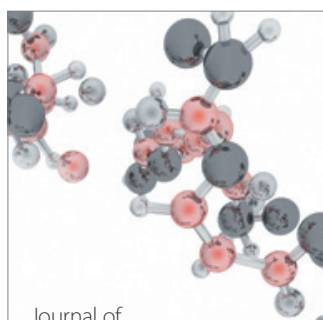

Analytical Methods

in Chemistry

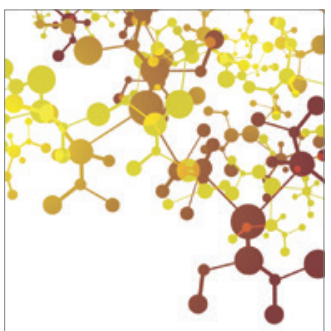

Journal of

Applied Chemistry

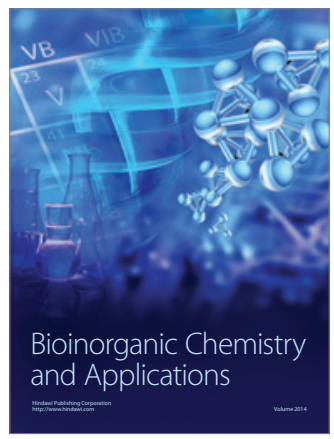

Inorganic Chemistry
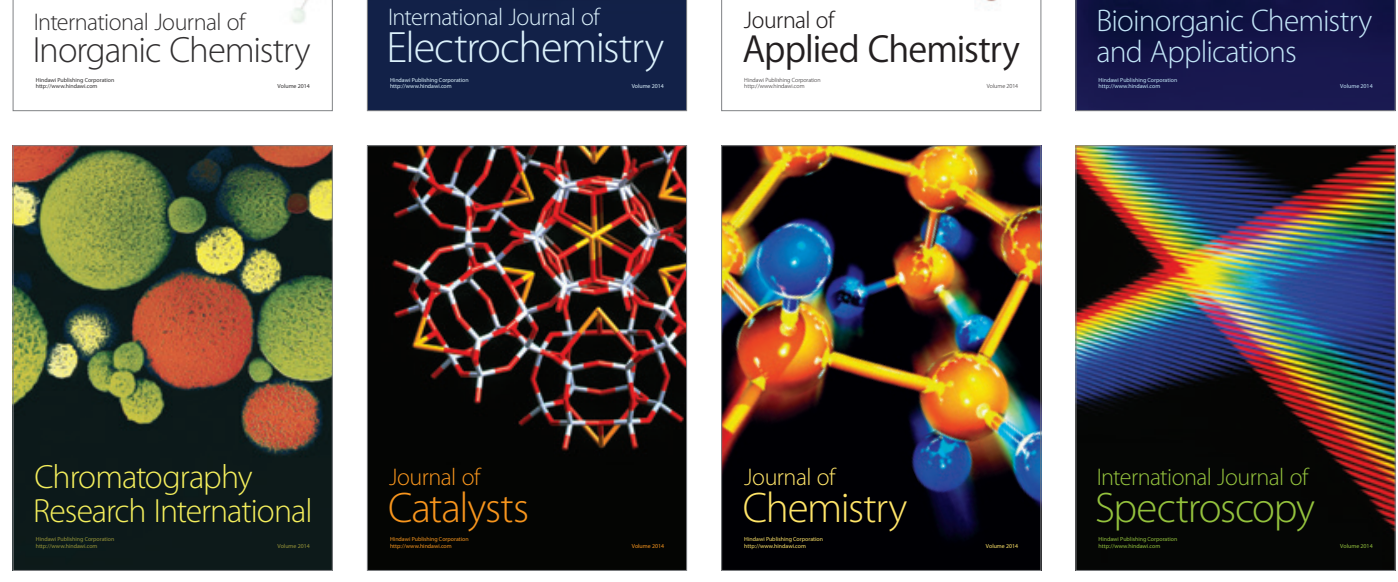